\title{
OS TRIBUNAIS E O DIREITO À SAÚDE
}

\author{
António José Avelãs Nunes e Fernando Facury Scaff, Porto \\ Alegre, Livraria do Advogado Editora, 2011
}

Fábio Ferreira Mazza*

\section{PARTE I - OS TRIBUNAIS E O DIREITO À SAÚDE}

O autor e professor António José Avelãs Nunes, responsável pela primeira parte desse livro, inicia descrevendo o Tribunal Constitucional (TC) português, suas características e funções e podemos perceber um universo muito diferente do brasileiro.

O tribunal português está integrado ao sistema político, sendo que a Constituição da República Portuguesa(1) (CRP) Ihe atribui a competência de administrar a justiça em matéria de natureza jurídico-constitucional (Art. 221, CRP). Porém, ao tratar da organização dos tribunais enquanto órgãos de soberania com competência para administrar a justiça em nome do povo (art. 202, CRP), a Constituição portuguesa diz que existem outras categorias de tribunais além do TC (Art. 201, CRP). Observamos então que o TC exerce uma função jurisdicional e não uma função política. O TC não está integrado na organização judiciária, sendo objeto de um título à parte. Pode-se dizer que o Tribunal Constitucional português é "um outro dos 'poderes' do Estado"(2), um órgão de soberania autônoma.

A função do TC é a de garantir que os órgãos do Estado e os seus titulares respeitem os normativos constitucionais no processo de formação e

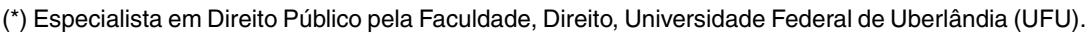
Pós-graduando em Direito Sanitário e mestrando em Saúde Pública, Faculdade de Saúde Pública, Universidade de São Paulo (FSP/USP). Advogado. São Paulo/SP - Brasil. E-mail: <fabiofmazza@ gmail.com>.

Recebida em 14.06.12

(1) PORTUGAL. Constituição da República Portuguesa. Disponível em: <http://www.parlamento.pt/ Legislacao/Documents/constpt2005.pdf>. Acesso em: 2 jul. 2012.

(2) NUNES, António José Avelãs Nunes apud DA COSTA, J. M. Cardoso. A jurisdição constitucional em Portugal, $3^{a}$. ed., Coimbra: Almedina, 2007. p. 23. 
determinação da vontade política e de adoção de decisões políticas. O TC é um órgão jurisdicional de controle normativo e apenas controla o processo político, por meio da declaração de inconstitucionalidade das decisões políticas "que se concretizam e exprimem em normas jurídicas”(3), não podendo apreciar a constitucionalidade das "normas privadas", dos "atos políticos" ou administrativos e nem das decisões judiciais (em regra). Também não lhe cabe proteger os direitos fundamentais por meio de ações diretas propostas junto ao próprio tribunal, bem como a competência para aplicar sanções aos titulares dos órgãos de soberania pela violação da Constituição.

Merecem destaque, segundo o autor, o controle preventivo da inconstitucionalidade das normas emanadas da Assembleia da República ou do Governo e a verificação de situações de inconstitucionalidade por omissão, realizados pelo TC com a finalidade de garantir o respeito das competências legislativas atribuídas na CRP à Assembleia e ao Governo. Estas competências fazem do TC um órgão que participa na formação da "vontade política" do Estado, embora confinando a sua participação no processo político ao controle da constitucionalidade das normas jurídicas.

No período de 1982 a 1989, o TC interferiu na definição e concretização de políticas públicas, por meio da influência de seus acórdãos, e atuou como um órgão político, oferecendo ao poder político uma interpretação da CRP "amiga do capitalismo" e legitimadora de todas as iniciativas tendentes a impedir a concretização dos objetivos constitucionais de construção de uma sociedade socialista.

Este foi o sentido do acórdão do TC pela não inconstitucionalidade da lei que autorizava o governo a cobrar taxas moderadoras pelo recurso ao Serviço Nacional de Saúde (SNS), considerado universal, geral e gratuito pela Constituição portuguesa(4). Em consequência, as taxas moderadoras passaram a ser obrigatoriamente pagas por todos os usuários do SNS (com exceção dos declarados isentos).

Posteriormente, em 1989, quando da revisão do texto da CRP, o SNS passou a ser considerado tendencialmente gratuito, conforme as condições econômicas e sociais dos cidadãos. Mais adiante, em 2005, o governo impôs o pagamento de taxas moderadoras por dia de internação hospitalar e por cada intervenção cirúrgica(5).

Com a política legitimada pelo TC, o SNS passou a ser um serviço limitado aos pobres, pois quem tem condições financeiras deve pagar pela utilização

(3) NUNES. op. cit., p. 98-103.

(4) Acórdão n. 330/88. Acórdãos do Tribunal Constitucional, Vol. 13, Tomo I.

(5) Conforme informado pelo autor, em nota de rodapé, em 2009, após as eleições legislativas e face da enorme impopularidade e contestação das taxas moderadoras, o Governo aprovou um decretolei para abolir estas taxas. Os partidos da oposição (inclusive os da direita) também aprovaram no Parlamento uma lei com o mesmo objetivo. 
dos serviços. Ocorreu aqui uma violação ao princípio da universalidade dos direitos sociais.

Para o autor, esta lógica de caridade pública (gratuidade dos serviços de saúde somente aos pobres) não encontra o mínimo conforto na CRP. A diferença de rendimentos entre as pessoas e grupos sociais deve-se restringir somente ao sistema fiscal e na contribuição às receitas do Estado.

Outro ponto importante abordado pelo autor trata da apreciação pelo TC da inconstitucionalidade por omissão. Atualmente, nos casos em que o tribunal concluir pela existência de inconstitucionalidade por omissão, a sua competência se esgota no ato de dar conhecimento do fato ao órgão legislativo competente, não havendo lugar a qualquer condenação do órgão legislativo em falta, nem a qualquer convite ou sugestão para que o órgão em falta cumpra o seu dever de legislar, muito menos se cogita a possibilidade do TC legislar para suprir a inconstitucionalidade por omissão. É afastada aqui qualquer ideia de judicialização da política ou do exercício pelos tribunais de qualquer outro poder do Estado que não seja o poder judicial e a função jurisdicional.

Em um segundo momento, o autor começa a discorrer sobre o entendimento corrente no Brasil.

No que tange à problemática em análise, o STF defende que está entre as competências do Poder Judiciário evitar que as omissões do poder político façam perecer os direitos fundamentais previstos na Constituição.

Na esfera do direito à saúde, são várias as decisões dos Tribunais de Justiça que reconhecem o dever do Estado de fornecer medicamentos ou tratamentos a pessoas doentes, condenando o Estado ao pagamento de multa diária em caso de descumprimento deste dever, sendo lícito inclusive (conforme decisão do STJ) que o magistrado determine o bloqueio de valores em contas públicas com o intuito de garantir o custeio de tratamento médico, concretizando-se desta forma os princípios da dignidade da pessoa humana e do direito à vida e à saúde. Também entende o STJ, que o legislador deixou ao arbítrio do magistrado a escolha das medidas que melhor se adequem a cada caso, conforme suas peculiaridades, podendo inclusive utilizar-se da medida coercitiva de bloqueio em conta do Estado. ${ }^{(6)}$

O autor entende que a posição adotada pelo STF, ao classificar como interesse financeiro e secundário do Estado a invocação pelo Executivo da escassez de recursos para atender os pretensos direitos subjetivos (de todos e de cada um), a fim de se obter os tratamentos ou os medicamentos que poderiam ajudar a recuperar a saúde, não pode ser levada a sério. Não que seja impossível encontrar recursos para satisfazer as pretensões exigidas; o fato é

(6) Agravo Regimental 750.966/RS, julgado em 09 de maio de 2006. Diário de Justiça, 19 de maio de 2006. p.203 
que não há recursos financeiros suficientes para atender sem limites todas as exigências quanto à satisfação plena dos direitos sociais, econômicos e culturais.

Para o autor, é difícil aceitar a tese da jurisprudência brasileira, onde o Poder Judiciário tem legitimidade para intervir nessa matéria, sempre que o Executivo não dê cumprimento às normas constitucionais a esse respeito. Não caberia ao Poder Judiciário controlar o cumprimento dos programas de governo apresentados pelo Executivo, caso ele adote políticas erradas ou insuficientes, ou deixe de adotar políticas; o juízo sobre seu comportamento é um juízo político que só cabe ao Parlamento e ao povo soberano.

Para Nunes, os tribunais não podem alterar os orçamentos aprovados pelo Legislativo e muito menos capturar verbas do orçamento da União, Estado ou alguma prefeitura, mandar deposita-las no Banco do Brasil e cometer a uma entidade pública o encargo de gastar aquela verba no cumprimento da decisão do tribunal. Da mesma forma, os tribunais não podem impor ao Executivo a inscrição, nos orçamentos de anos vindouros, das verbas que serão destinadas a realização dos objetivos políticos que eles julgam prioritários. Os tribunais não podem fazer opções políticas, esta não é sua função soberana.

Em outro momento, o autor faz referência a um interessante raciocínio, ao levar em consideração o princípio da dignidade humana. Assim como a saúde, o direito ao trabalho, a educação e também a moradia são considerados direitos sociais; mas, não vemos os tribunais determinando que o Estado proporcione um posto de trabalho a um trabalhador que perdeu um emprego contra sua vontade e nem que o Estado adote medidas necessárias para que este trabalhador tenha este seu direito fundamental garantido, podendo exercer sua profissão e ganhar assim sua vida. Também não vemos os tribunais condenando o Estado pela má qualidade dos serviços públicos de educação, exigindo que os níveis sejam igualados ao das melhores escolas particulares, por ser este um direito fundamental inerte à todos.

Também é bem lembrada por Nunes a questão do acesso à justiça. A maioria dos mais necessitados não tem acesso a um tribunal. Nesta órbita, os recursos aos tribunais para fazer valer direitos individuais (direito à saúde ou qualquer outro direito social) não torna esses direitos efetivos para todos, apenas aumenta as desigualdades e as injustiças resultantes de vários fatores.

Por fim, a primeira parte do livro termina com o autor se mostrando contrário a exploração característica em nossas sociedades capitalistas, que acaba gerando uma imensa exclusão social. Nunes alega que a separação dos poderes é tida como uma invenção do estado burguês e que somente por uma ruptura revolucionária é que se poderá ultrapassar tais limitações, sendo que ninguém que queira subverter o estado de classe da ordem burguesa-capitalista confiará tal tarefa aos juízes. Os juízes, em alguns casos, substituem não só o Executivo, mas também o povo (que não foi consultado na definição das prioridades das políticas públicas), e é verdade que o povo elege os titulares dos cargos políticos, não elege os juízes. 
Nas sociedades de classes, o Estado é um estado de classe. Os tribunais fazem parte deste estado de classe e é perigoso admitir que eles possam substituir o estado democrático, constituindo-se numa espécie de estado acima das classes. O estado tecnocrático carrega consigo o perigo de um dia querer acabar com a política e a luta de classes. O mundo já conheceu uma experiência deste tipo e com certeza não quer regressar a ela.

\section{PARTE II - DIREITO À SAÚDE E OS TRIBUNAIS}

A segunda parte do livro, escrita pelo professor Fernando Facury Scaff, tem como objetivo analisar o direito à saúde e sua aplicação pelos tribunais brasileiros, que muitas vezes concedem de forma direta aos jurisdicionados medicamentos e tratamentos de saúde que não estão previstos nos documentos orçamentários do Poder Público, gerando assim um custo imediato e imprevisto.

Desta forma, o autor inicia o diálogo através da contextualização do surgimento dos direitos sociais e do direito à saúde na Constituição de 1988, explicitando de que forma tais direitos foram inseridos em nosso texto constitucional. Discorre em específico sobre os termos através dos quais deve ser compreendido o direito à saúde, ou seja, os artigos 23, 24,194,196, 197, 198, e 200 da CF.

Não existem direitos sem custos, segundo Scaff. Não apenas os direitos sociais, mas todo e qualquer direito, fundamental ou não, possui um custo. Assim, sob a égide do princípio da solidariedade, o custo dos direitos fundamentais deve ser financiado por toda a sociedade, por meio de um sistema tributário, principalmente quando se fala de direitos sociais, pois estes implicam fortes dispêndios e ações por parte do Estado.

Logo, o estudo dos direitos sociais deve manter relação com o direito financeiro, sendo a análise sobre como o Estado arrecada, gasta e se endivida, de primordial importância para a compreensão da temática dos direitos sociais. As receitas públicas, os gastos públicos e o crédito público, bem como a aplicação coordenada destes (o orçamento) tem estreita relação com os direitos sociais.

Pelo prisma dos direitos sociais, o estudo do Direito Financeiro se alicerçaria nos principais tópicos: A Receita Pública (analisa quem paga as contas); As Renúncias Fiscais (tratam de quem deixa de pagar a conta); O Gasto Público (trata de quem recebe as prestações sociais, em outras palavras, são os dispêndios do Estado); O Crédito Público (implica saber qual geração pagará a conta); O Orçamento Público (estudo como o Estado organiza os itens anteriores.

Assim, é necessário compreender a estrutura do sistema orçamentário brasileiro e seus institutos, para um melhor entendimento dos temas trazidos por esta obra. Neste sentido surge a questão já levantada e tão veemente posicionada na primeira parte, sobre de que forma o Poder Judiciário pode dispor 
do direito à saúde ou se isto é de exclusiva competência dos demais Poderes (Legislativo e Executivo).

A Constituição brasileira previu os recursos para custeio dos direitos sociais, estabelecendo sua fonte de custeio, caracterizando assim uma garantia financeira para sua efetiva prestação à sociedade. Existem recursos mínimos assegurados pela Constituição aos entes federativos, permitindo assim que a Seguridade Social seja mantida (Assistência Social, Previdência Social e Saúde Pública), conforme estipulado no Art. 195 da CF.

Outras fontes de custeio também podem ser criadas por lei complementar, sendo que o direito à saúde se beneficia de fontes próprias de financiamento, conforme elencado no Art. $198, \S 1^{\circ}$ da CF. Desta forma, fica estabelecido as fontes orçamentárias para o custeio dos gastos com o SUS, abrindo também a possibilidade de outras fontes de recursos virem a ser estabelecidas. Além disso, a Constituição também prevê recursos mínimos a serem direcionados a este tipo de gasto por cada ente federativo, determinado pelos parágrafos $2^{\circ} \mathrm{e}$ $3^{\circ}$ do Art. 198, que mais recentemente teve, em seu $\S 3^{\circ}$, regulamentado a lei complementar de que trata ${ }^{(7)}$.

Em suma, pode-se entender que o SUS, sistema responsável pela implementação da política de saúde pública no Brasil, é financiado por parcela orçamentária dos recursos destinados à Seguridade Social e também pela União, Distrito Federal e Municípios.

O custeio do direito à saúde no Brasil é cuidadosamente regulado pela Constituição e isto é de grande importância, pois esta fonte de custeio que se constitui em verdadeira garantia financeira para a consecução do direito à saúde decorre da contribuição para o sistema tributário brasileiro. O desembolso compulsório de todas as pessoas que são contribuintes do sistema tributário, também financia o direito à saúde no Brasil.

Feitas estas considerações, o autor passa a examinar quem deve receber as prestações e ações de saúde, já alertando que aqui os problemas se agigantam, pois, em tese os beneficiários são todos os que habitam no país, incluindo os estrangeiros, em face dos objetivos fundamentais de nossa república constantes no Art. $3^{\circ}$ da CF.

No entanto, ainda assim não se encontram respostas para certas questões. Quem estabelece as prioridades no gasto público? O Estado deve gastar em

(7) Sancionada em janeiro de 2012 pela presidente Dilma Rousseff, a regulamentação da Emenda 29 dispõe que os Estados deverão investir em saúde no mínimo 12\% do que arrecadam com impostos e transferências, enquanto os municípios destinarão no mínimo $15 \%$ destas mesmas receitas. A União investirá o mesmo montante do ano anterior, acrescido da variação nominal do Produto Interno Bruto (PIB). No texto original da segunda parte do livro ora resenhado, o autor Fernando Facury Scaff não faz referência ao citado acontecimento, limitando-se a analisar o que ocorria de fato até o ano de 2011, antes da sanção presidencial. 
favor de quem? Quem estabelece quais serão os destinatários e as prioridades dos gastos públicos com saúde no Brasil?

Por exemplo, por que se deve tratar com prioridade as enfermidades decorrentes da AIDS do que da catapora ou malária? Qual o critério que indica que não haveria opção mais adequada que não a efetuada? Busca-se, nestes casos, esclarecer quem tem a primeira e principal escolha trágica sobre quais serão os destinatários e as prioridades dos gastos públicos com saúde no Brasil. Esta responsabilidade cabe ao Parlamento, por meio de um mecanismo de planejamento denominado Sistema Orçamentário, composto por três leis: Plano Plurianual, Lei de Diretrizes Orçamentárias e Lei Orçamentária Anual, conforme disposto no Art. 165 da Constituição.

Ao tratar das posições dos tribunais superiores brasileiros (STJ e STF), Fernando Scaff contempla a segunda parte desta obra com vários fragmentos de decisões interessantes destes tribunais.

No caso do STJ, tribunal uniformizador da jurisprudência infraconstitucional, centenas de casos já foram apreciados. Percebe-se que este tribunal tem decidido no sentido de se conceder os pedidos contidos nas demandas relativas à saúde (coletivas ou individuais), mas também as tem negado. A bem da verdade, ainda são poucos os ministros que possuem clareza de entendimento o suficiente para negar tais demandas, sob os argumentos dos princípios democráticos, da isonomia e da reserva do possível. A questão fica ainda mais complexa quando o STJ entende, no caso do fornecimento de medicamentos, não ser este um tema complexo, podendo ser resolvido sem matéria probatória e, utilizando vasta decisões, transferindo tais casos para os Juizados Especiais Federais, quando o valor em debate for inferior a sessenta salários mínimos.

Desse modo, o controle dos Tribunais Regionais ou superiores foi ainda mais reduzido, pois transferiu a deliberação sobre este tipo de questão aos Juizados Especiais, sem necessidade da análise probatória, encerrando a discussão em uma única instância. Apenas será diferente quando houver afronta constitucional, porém a hipótese dessa hipótese ser acatada pelo STF é remota.

Já no tocante à posição do STF, deve-se considerar dois momentos distintos: julgamento ocorridos antes e depois das audiências públicas realizadas pelo STF para debater a judicialização do direito à saúde, em abril e maio de 2009.

Antes das audiências de 2009, várias decisões reconheceram o direito à saúde. Nesse sentido, o autor discorre sobre as mais emblemáticas, sendo uma das mais citadas a Petição 1.246-1(8), de Santa Catarina, com a relatoria do Ministro Celso de Mello. Esta decisão vem sendo reiteradamente mencionada pelo STF como paradigma do seu reconhecimento do direito à saúde. Cumpre ressaltar aqui que o STF optou por não enfrentar o caso, ficando assim prejudicado a

(8) Agravo Regimental Petição n 1246-1 - SC. 
apreciação do mérito do pedido e consequentemente o debate. Mas, as razões contidas na decisão singular do Ministro Celso de Mello permanecem até hoje como fundamento das demais decisões da Corte.

Outro caso que merece destaque, julgado antes das audiências, é o julgamento da Arguição de Descumprimento de Preceito Fundamental - ADPF 45, em 2004, da qual foi relator também o Ministro Celso de Mello e que segue o mesmo caminho de proclamações sem nenhuma deliberação no caso concreto. Mesmo não sendo um acórdão, esta é uma das mais citadas decisões do STF. Trata-se de uma discussão sobre a aplicabilidade das normas constitucionais, em especial sobre o direito à saúde, mas cuja deliberação se conteve à singela proclamação monocrática: "julgo prejudicada a presente arguição de descumprimento de preceito fundamental, em virtude de perda superveniente de seu objeto".

Após a realização das audiências públicas em 2009, o STF criou balizas jurisprudenciais para a análise de pedidos relativos ao direito à saúde. A decisão originária dos debates foi a exarada no Agravo Regimental da Suspensão da Tutela Antecipada - AgReg STA 175-CE, de 17 de março de 2010, com a relatoria do Ministro Gilmar Mendes. Trata-se de um caso de concessão de medicamentos à pessoa física hipossuficiente, mediante tutela antecipada concedida em sede de apelação cível pelo Tribunal Regional Federal da $5^{\text {a }}$ Região, que teve sua suspensão negada de forma monocrática pelo Presidente do STF, ensejando o agravo em questão, que também foi negado, por unanimidade, sob o fundamento de que não havia indícios de "grave lesão à ordem, à economia e à saúde públicas".

Ai analisar esse caso, Scaff, mais uma vez, elucida de forma brilhante a decisão processual, narrando cada etapa do debate, analisando os pontos discutidos e traçando comentários pertinentes. Mas, embora represente a citada decisão um grande avanço jurisprudencial na matéria em análise, por destrinchar vários pontos e questionamentos, o STF não dirimiu completamente o problema, deixando ainda brechas para transformar os cofres públicos em instrumento de custeio de planos de saúde individuais através de ações individuais ou coletivas.

Já a título de conclusão, Scaff comenta sobre o direito à saúde, norma programática e interesses difusos.

Seria o direito à saúde uma norma programática? Veicularia direitos passíveis de subsunção ao Poder Judiciário visando à obtenção de prestações individualizadas de saúde? O Poder Judiciário pratica justiça comutativa e não distributiva, faz microjustiça e não macrojustiça. Não quer dizer, entretanto, que o direito à saúde tenha uma função meramente programática, sem efetividade e que não possa ter sua ação submetida ao Judiciário; ao contrário disso.

Mas, seu melhor uso não é para a obtenção de direitos individuais ou para um determinado grupo de pessoas. A implementação do direito à saúde 
deve ser focado na formulação de políticas públicas de saúde e não na busca individualizada de medicamentos ou ações correlatas. Deve-se buscar, por meio da formulação de protocolos pela Administração Pública, o estabelecimento de ações adequadas e compatíveis com os recursos públicos disponibilizados.

E aqui não há problemas em se buscar o Judiciário para que sejam inseridos, nos referidos Protocolos, determinados procedimentos ou medicamentos não contemplados, ou para que se faça uma severa fiscalização na aplicação dos recursos públicos destinados a essa atividade. O importante e imprescindível é que haja a busca de realização de uma justiça para todos, visando ao bem comum.

Diferentemente do que várias decisões judiciais estabelecem, Scaff entende que o direito à saúde não deve ser compreendido individualmente, mas sim, de maneira compreensiva ao bem comum, às efetivas e reais condições de possibilidade para uma existência de todos em sociedade. $O$ direito à saúde não é uma norma programática sem eficácia, ela tem plena eficácia e vincula todo o Poder Público; mas, ao dar ensejo a prestações individuais, não realiza justiça comutativa e assim não implementa direitos sociais. $O$ direito à saúde não consagra direitos individuais e sim difusos, que devem ser obtidos sob a forma da justiça distributiva, mais facilmente realizável por meio dos Poderes Legislativo e Executivo do que por via judicial individual.

Por fim, Scaff apresenta um raciocínio interessante ao propor que grande parte dos problemas na área da saúde seria resolvida, se fosse adotada a obrigação, em âmbito constitucional, de que os eleitos e suas famílias devessem necessariamente utilizar os hospitais públicos. Tal atitude seria uma injeção de estímulo no SUS, que passaria a contar com mais recursos e melhor cuidado em sua aplicação. O problema seria saber se essa norma passaria pelo Congresso Nacional. 